\title{
Spectrochemical Determination of Small Amount of Aluminium in Steel ${ }^{*}$
}

\author{
By Zenichiro Takao** \\ and Satoshi Miyoshi***
}

\section{Synopsis}

Determination of the total aluminium in steel is of essential importance, because it makes a vital basis decisive to a series of problems in the structure and composition of steel.

A spectrographic analysis described below applicable to minute total aluminium $(0.005-0.100 \%)$ in steel was established by means of a combined use of a medium sized quartz spectrograph and a grating spectrograph of the Ebert type with an $\mathrm{AC}$ intermittent arc as a source unit.

Precision in terms of the coefficient of variation reached $3-5 \%$, while accuracy achieved was comparable to results obtained by wet chemical analysis.

Austenite grain size could be measured by this method within a few hours after ingot making, which helped insure the quality of the steel product.

\section{Preface}

It is a well-known fact that austenitic grain size greatly influences the properties of steel. It is, therefore, an important task in the steelmaking process to produce a steel with a desired austenite grain size. Aluminium is a metal that has been utilized as a controlling agent for grain size of steel since the early days. To make clear the processes of grain-size refining and the establishment of controlling techniques for austenitic grain size in actual operations, one of the authors investigated the methods of separation and determination of the aluminium and its compounds in steel,1) chemical metallurgy of aluminium in steel, -2 the effects of aluminium on austenitic grain size of chromium-molybdenum case-hardening steel'2)3) and the methods of controlling austenitic grain size $\mathrm{e}^{+}$in actual operations.

As the result, it has been concluded that a rapid and precise determination of the aluminium in steel, as well as an earlier evaluation of the effect of controlling the effect of grain size are very important for technical management. Chemical analysis is complicated in the operation, and requires much time and so in analyzing samples of many charges, there is difficulty in handling them.

The authors then noticed that the spectrographical method could be used for this purpose. In the early stage, principally, the authors examined the problem with the medium sized quartz prism spectrograph, then later, with the Ebert type grating spectrograph. They obtained satisfactory results for accuracy and the necessary expense and time reductions. The results of the authors' ex- periment are summarized as follows:

\section{Apparatus}

Spectrographs: a medium-size quartz spectrographs (NQM-60 type), an Ebert type grating spectrograph (GE-340 type). Excitation unit: Pfleilsticker type intermittent A.C. arc-source unit. Densitometer: a non-recording micro-photometer.

\section{Procedure of Spectral Analysis}

The supplied samples were ladle samples, blooms and billets. Each pin-type sample in the selfelectrode and the disc-type samples in setting the counter electrode, (they have the analytical gap length of $2 \mathrm{~mm}$, respectively), under conditions of an intermittent arc of A.C. $220 \mathrm{~V}$ 3-6 A (intermittent ratio of $1: 10$ and intermittent frequency of once each sec.), was preburned and exposed for 20-40 s. and the spectrogram was obtained.

The plate obtained for the medium-sized quartz spectrograph (Fe 3116.63 $\mathrm{A}) /(\mathrm{Al} 3082.16 \AA)$ was used as an analysis line pair in the density comparison method and in the grating spectrograph, Al $3082.16 \AA / \mathrm{Fe} \quad 3093.36 \AA$ or $\mathrm{Al} 3082.16 \AA / \mathrm{Fe}$ $3095.27 \AA$ as analysis line pairs in the intensity comparison method. The total aluminum in steel $0.005-0.100 \%$, was determined.

The test of a pin sample for the ladle sample and a disc sample was done by chill-casting in small molds, as shown in Photos 1 and 2. For polishing and shaping of the discharge surface of samples, a grinder of silicon carbide was used.

\section{Study-Testing and Investigation}

\section{Analytical Line}

Table 1 lists the spectral lines used for the analysis of aluminium.

As an analytical line for aluminium, the following four neutral atomic spectrum lines are considered.

With a medium quartz spectrograph, Al 3961A and Al $3944 \AA$ can not be used because of an interference and an overlapping of the adjacent lines of Fe or Mo. Al $3092 \AA$ can not be used for vanadiumcontaining steel because of interference of $\mathrm{V}$ 3093.$13 \AA$. Al $3082.155 \AA$ is the only analysis line which can be used. In this case any interference or overlapping of other spectral lines can almost be

* Lecture delivered before the 58th Grand Lecture Meeting of the Iron and Steel Institute of Japan on Nov. 3rd, 1959 in Osaka. Japanese text was printed in "Tetsu-to-Hagané" (Journal, Iron \& Steel Institute, Japan) Vol. 47, No. 2 pp. 145-152.

* Dr. Eng., Central Research \& Development Lab., Kobe Steel Works, Ltd.

*** Central Research \& Development Lab., Kobe Steel Works, Ltd. 


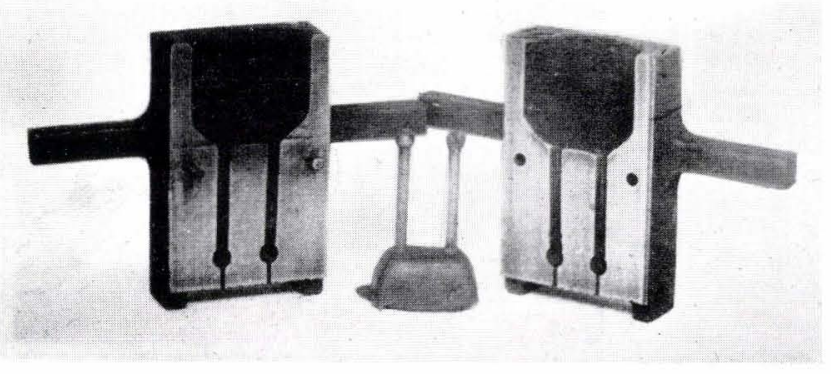

Photo 1. Mold for pin sample (100 $\mathrm{ml}$ vol.)

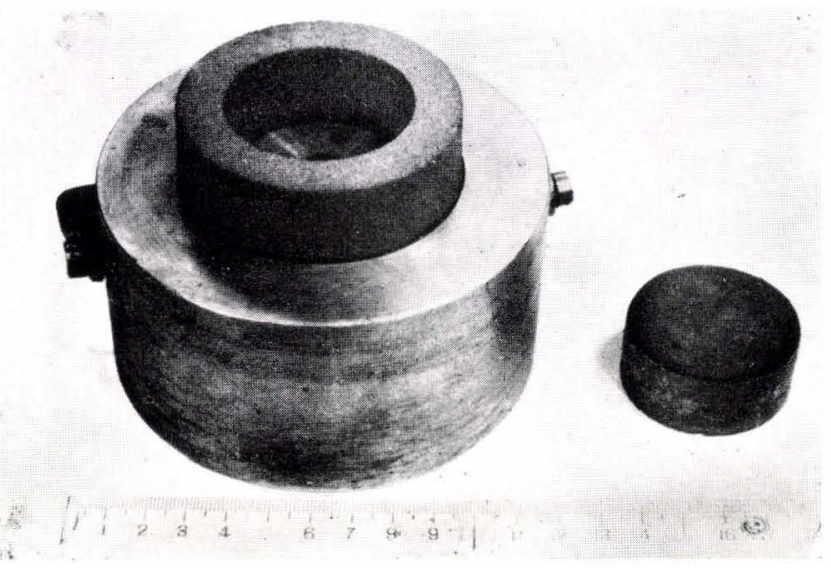

Photo 2. Mold for disc sample $(40 \mathrm{ml}$ vol.

Table 1. Analysis line of $\mathrm{Al}$

\begin{tabular}{c|c|c|c}
\hline \multirow{2}{*}{ Wave-length $\AA$} & \multicolumn{2}{c}{ Intensity } & Sensitivity \\
\hline 3961.527 & Arc & Spark & \\
\hline 3944.032 & 3,000 & 2,000 & $\mathrm{U} 1$ \\
\hline 3092.713 & 2,000 & 1,000 & $\mathrm{U} 2$ \\
\hline 3082.155 & 1,000 & 1,000 & $\mathrm{U} \mathrm{3}$ \\
\hline
\end{tabular}

ignored.

On the other hand, if the second order spectra of Ebert type grating spectrograph (dispersion of $2.5 \AA / \mathrm{mm}$ ) are used, the above difficulty in a medium spectrograph can be avoided.

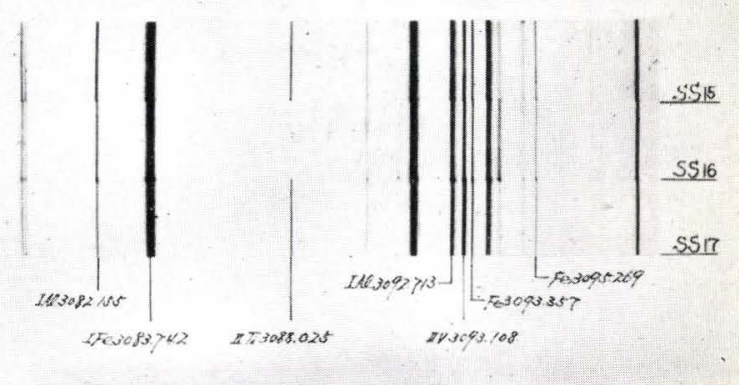

Photo 3. Photograph taken by Ebert type grating spectrograph

The authors decided to use Al $3082.16 \AA$ as the analytical line in consideration of the photographic wave-length region for simultaneous determination of the small amount of other elements (such as $\mathrm{Sn}, \mathrm{Ti}, \mathrm{V}, \mathrm{Co}, \mathrm{Ni}, \mathrm{Cr}, \mathrm{Cu}$, etc.) and for the concentration range in practical analysis.

Photo 3 shows the spectrogram taken by a grating spectrograph.

\section{Shape of the Electrode}

As a standard for evaluating the sensitivity with a constant $\mathrm{Al}$ concentration a length of exposure period was chosen so that the intensity of the spectral line becomes 1.3 times that of the background intensity. The conditions of the superior reproducibility for the electrode shape, the arc current and other factors were studied with the medium quartz spectrograph.

In connection with the self electrode, three types a) $90^{\circ}$ cone-type, b) roof-type of $1 \mathrm{~mm}$ square, c) point to plane-type, were taken up. In the counter electrode method, d) copper rod or e) carbon rod, all in $120^{\circ}$ cone shapes were used and with arc current of $5 \mathrm{~A}$, photographs were taken five times in succession, and the reproducibility was tested. The results showed that both the self electrode and the counter electrode (of carbon rod) provided superior results in the point to plane-type, respectively (cf. Table 2).

Two kinds of plates were used in these tests.

Table 2. Coefficient of variation on the electrode combination of several types

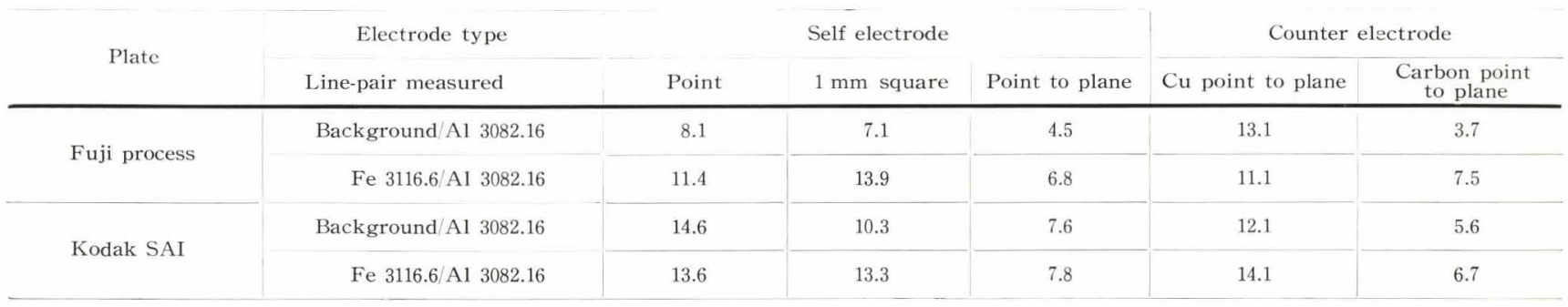




\section{Arc Current}

Arc currents were grouped in 5 grades of 3,5 , 10,13 , and $18 \mathrm{~A}$, the sensitivity of analytical line, and the relation of the density difference between analytical line pairs were studied. The study showed that $3 \mathrm{~A}$ gave good results for the selfelectrode method and that $6 \mathrm{~A}$ was best for the counter electrode method.

It was found that when current went over $10 \mathrm{~A}$, in the case of i) self electrode, even with the middle diaphragm, the exposure period was found to be too short. In the case of ii) counter-electrode, some lowering of precision was observed. For example, the carbon rod consumption became great, and during exposure, the gap length of electrode gradually opened.

With the same testing specimen (Al $0.014 \%$ ), 4 operators took eleven sets of photographs of cases 1 to 5 at random, and measured the reproducibility of each analytical line pair density difference. The results are as shown in Table 3 .

Table 3. Reproducibility test (preliminary experiments)

\begin{tabular}{|c|c|c|c|c|c|c|c|c|c|c|}
\hline \multicolumn{6}{|c|}{ Operating conditions } & \multicolumn{5}{|c|}{ Results obtained } \\
\hline \multirow{2}{*}{\multicolumn{2}{|c|}{ Method }} & \multirow{3}{*}{$\begin{array}{c}\begin{array}{c}\text { Types of } \\
\text { electrode } \\
\text { combination }\end{array} \\
\text { Self }\end{array}$} & \multirow{3}{*}{$\begin{array}{c}\text { Diaphragm } \\
\text { No use }\end{array}$} & \multirow{3}{*}{$\begin{array}{c}\begin{array}{c}\text { Arc } \\
\text { current } \\
(\mathrm{A})\end{array} \\
3\end{array}$} & \multirow{3}{*}{$\begin{array}{c}\frac{\begin{array}{c}\text { Experiment } \\
\text { time } \\
(\mathrm{S})\end{array}}{20}\end{array}$} & \multicolumn{4}{|c|}{ Operators } & \multirow{2}{*}{$\begin{array}{c}\text { Average } \\
(\%)\end{array}$} \\
\hline & & & & & & A & B & $\mathrm{C}$ & $\mathrm{D}$ & \\
\hline Case & 1 & & & & & 3.3 & 7.6 & 4.4 & 4.7 & 5.0 \\
\hline & 2 & Counter & " & 6 & 20 & 4.0 & 4.0 & 6.5 & 7.2 & 5.4 \\
\hline & 3 & Self & Use & 10 & 8 & 8.5 & 11.5 & 9.1 & 8.0 & 9.3 \\
\hline & 4 & Self & ” & 6 & 27 & 5.9 & 5.6 & 3.5 & 8.9 & 6.0 \\
\hline & 5 & Counter & $"$ & 10 & 25 & 8.8 & 10.0 & 9.0 & 8.7 & 9.1 \\
\hline
\end{tabular}

\section{Al, Alumina, Aluminum Nitride and Their Be- haviour in Excitation Period}

The spectrographic analysis methodsi)(i)7)8 of aluminum in steel in the U.S.A. and Europe during 1940-1949, in almost all cases, employed the solution method and measured each $\Sigma \mathrm{Al}$, soluble Al and insoluble $\mathrm{Al}$ by chemical pretreatment.

Castro5) studied the subject, when $\mathrm{Al}$ content was within the range of $0.004-0.15 \%$. "The results showed that the essential difficulty in spectrochemical analysis lies in the fact that both soluble and insoluble $\mathrm{Al}$ (alumina and aluminium compounds in the state of inclusions) exist therein.

"The spark method, using the metallic electrodes, gives accurate results only with the soluble Al. Therefore, as long as there exists some Al (however little it might be) the solution method must be adopted. With the metallic electrode method, as the alumina distribution in steel is irregular and as the spectrographic sensitivity of alumina is too low, the spectrographical value can be obtained in between soluble $\mathrm{Al}$ and $\Sigma \mathrm{Al} . "$

On the other hand, in recent years, it was found at the Timken Roller Bearing Co.9) by determining $\Sigma \mathrm{Al}$ in ladle sample by means of Quantometer and from the significant correlation between McQuaid-Ehn grain size of products itself and quantometrical value of $\Sigma \mathrm{Al}$, the difference be- tween coarse-grain steel and fine-grain steel are distinguished. It is not the spark method which the authors used, but the intermittent arc method. The multi-source type discharge by Quantometer is also an arc-like interrupted discharge.

With the analytical method which the authors established, according to the experimental facts, no fractionally distilled vaporization is found between mutual relations of $\mathrm{Al}$, alumina and aluminum nitride. As the result of their uniform contribution toward emission it was found that the value of the determination can be obtained as $\Sigma$ Al.

\section{i. Lineality of Working Curve}

The standard samples used in this study were prepared as follows. After the raw material, lowcarbon refined steel, was melted in the $100 \mathrm{KVA}$ basic high-frequency induction furnace, it was added to $\mathrm{Al}$ in the ladle and cast into $15 \mathrm{~kg}$ ingots. These were forged into sections $15 \mathrm{~mm}$ square (F.R. $=10)$. Six charges of the forged pieces were selected from 20-30 charges and used after being further forged into $8 \mathrm{~mm}$ squares. The chemical composition, as shown in Table 4, is approximately $0.001-0.1 \% \mathrm{Al}$ in $\Sigma \mathrm{Al}$ and alumina and $\mathrm{Al}$ nitride are each ranged in $0.001-0.01 \%$. When $\Sigma \mathrm{Al}$ value of this standard sample was plotted to the analytical line pairs-density difference, a smooth working curve as shown in Fig. 1 was obtained. 
Table 4. Composition of standards, \% (used for analysis with the medium quartz spectrograph)

\begin{tabular}{|c|c|c|c|c|c|c|c|c|c|c|c|}
\hline St'd & C & $\mathrm{Mn}$ & $\mathrm{Si}$ & $\mathrm{P}$ & $\mathrm{S}$ & $\mathrm{Cu}$ & $\mathrm{Ni}$ & $\mathrm{Cr}$ & Mo & $\begin{array}{r}\mathrm{As} \mathrm{Al} \\
\left(\mathrm{Al}_{2} \mathrm{O}_{3}\right) \\
\end{array}$ & $\mathrm{IAl}$ \\
\hline$A-1$ & 0.21 & 0.65 & 0.41 & 0.009 & 0.015 & 0.03 & 0.01 & 0.08 & None & 0.003 & 0.014 \\
\hline 2 & 0.21 & 0.65 & 0.41 & 0.009 & 0.015 & 0.03 & 0.02 & 0.05 & " & 0.011 & 0.032 \\
\hline 4 & 0.20 & 0.65 & 0.39 & 0.009 & 0.014 & 0.03 & 0.04 & 0.06 & y & 0.009 & 0.069 \\
\hline 5 & 0.19 & 0.64 & 0.41 & 0.009 & 0.013 & 0.03 & 0.05 & 0.06 & " & 0.011 & 0.118 \\
\hline 6 & 0.23 & 0.69 & 0.40 & 0.011 & 0.015 & 0.03 & 0.01 & 0.09 & , & 0.0017 & 0.0054 \\
\hline 8 & 0.21 & 0.69 & 0.40 & 0.011 & 0.015 & 0.03 & 0.01 & 0.04 & " & 0.0017 & 0.0089 \\
\hline
\end{tabular}

ii. Approximate Best Coincidence of the Spectral Analysis Value and the Value of the Wet Chemical Analysis

As described below, 10 charges of samples with different Al combinations were melted for testing. After forging (F.R.=10) each of them was examined by chemical analysis and by this method and then both results were compared.

Al type sample: Electrolytic iron melted, in vacuum and after gas extraction, $\mathrm{Al}$ is added in the furnace.

AlN type sample: Adding $\mathrm{CaCN}_{2}$ in the furnace, and after adding nitrogen, $\mathrm{Al}$ was added in the ladle.

$\mathrm{Al}_{2} \mathrm{O}_{3}$ type sample: After usual melting, $\mathrm{Al}$ was added in the ladle.

From the results of chemical analysis of 37 charges, included in the range of $0.010-0.100 \%$ in form of $\Sigma \mathrm{Al}$, no bias was found between chemical and spectral analysis values. The coefficient of variation for the difference between the two (spectral value and chemical value) was $17.5 \%$. With different combination states of $\mathrm{Al}$ and notwithstanding an analysis of a minute quantity of $\Sigma \mathrm{Al}$, it may be said the authors have reached a good coincidence.

As another example of accuracy, the comparisons of chemical analysis and spectrographic analysis made with ladle samples are shown in Table 5 .

As shown in the table, no significant difference was observed between the two.

\section{iii. Results of Experiments with Chemical Reagents}

Next, the authors performed experiments with powder briquets. They used $\mathrm{Al}$ and alumina of analytical reagents (special grade). Also they employed aluminum nitride made by nitriding Al with refined ammonia gas. Pure carbon powder (screened through 200 mesh) was used as a binder and tablets were made by the following method.

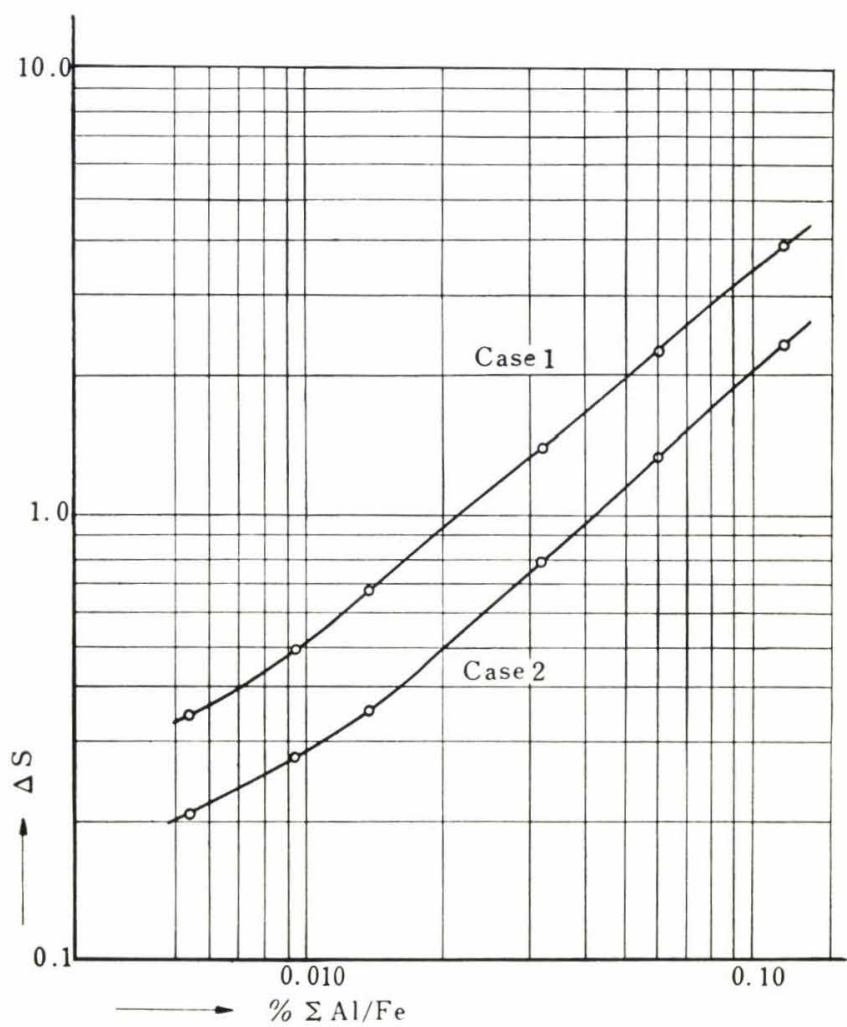

Fig. 1. Working curves (using medium quartz spectrograph)

The above reagents, after fixed quantity was weighed accurately in the quantity as shown in Table 6, were put in a porcelain dish, butyl alcohol in a rate of $1.5 \mathrm{ml} / \mathrm{g}$, made into a paste form was added and both were dried over a water bath for one hour. After mixing well with a glass paddle, further drying was done in an air oven at $110^{\circ} \mathrm{C}$ for one hour. The synthetic powder was formed into $1 \mathrm{gr}$ tablets ( $15 \mathrm{~mm}$ diameter, $4 \mathrm{~mm}$ thick) by pressing with a tablet shaper. These were made as an unknown test sample (U4-U6), and tablets were made with mixture of $\mathrm{Al}$ and carbon powder alone (by the same method) as a series of standard samples (S-1-S-3). The above three unknown test 
samples (with alumina alone, Al nitride alone, and the mixture of $\mathrm{Al}$, alumina and $\mathrm{Al}$ nitride) were analyzed. The results obtained are shown in Table
6. They showed that the additional quantity and analytical value coincided within $\pm 10 \%$ or less as $\Sigma$ Al.

Table 5. Comparison of results of the chemical and the spectral analysis using a medium quartz spectrograph

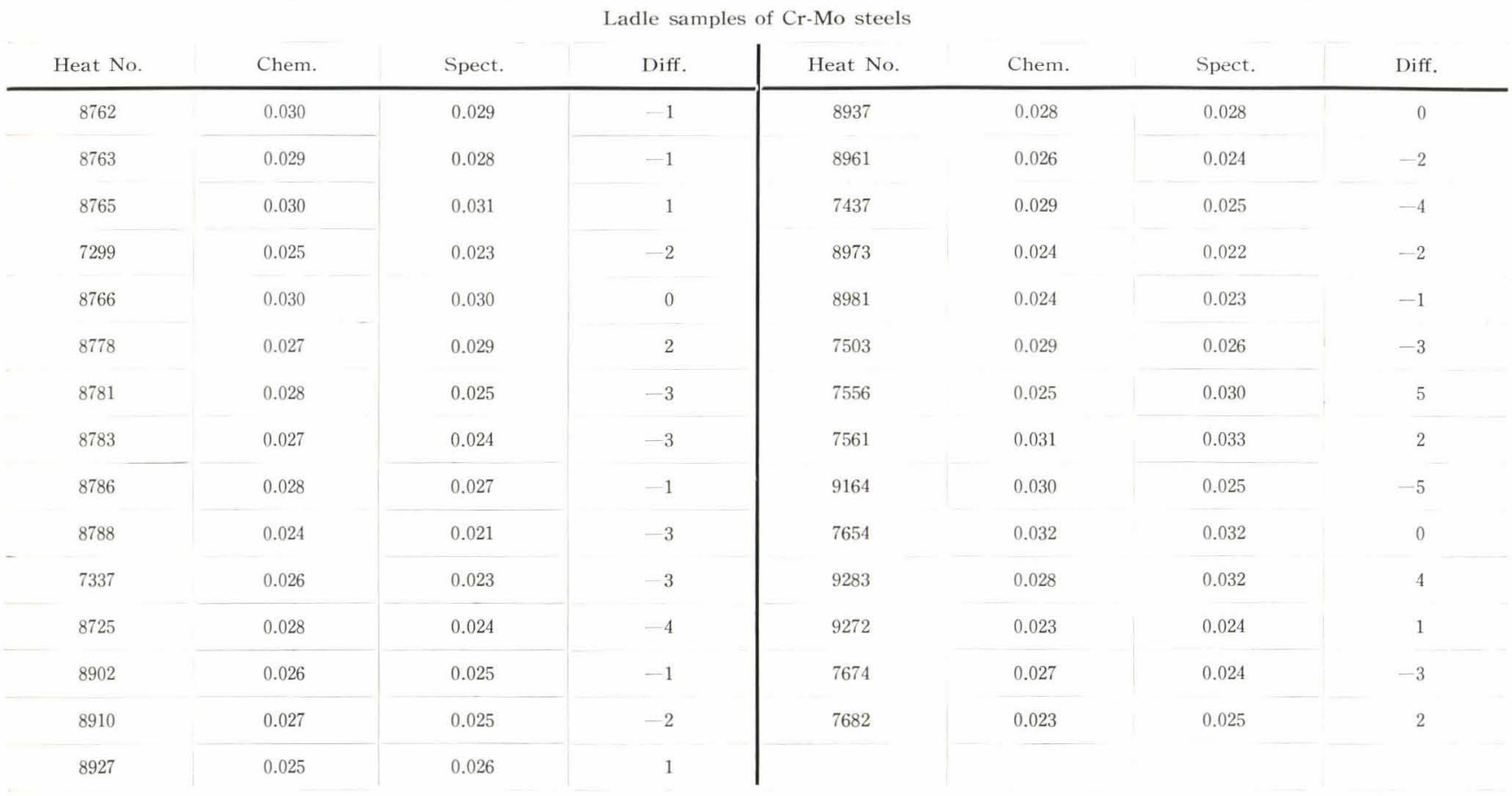

(Note) $n=29, \bar{d}=0.0008_{6}, \quad \sigma_{\ell}=0.0024_{2}, t_{0}=1.92<t(28,0.05)=2.048$

Table 6. Composition of synthetic samples and analytical results

\begin{tabular}{|c|c|c|c|c|c|c|c|c|}
\hline & $\begin{array}{c}\text { Sample } \\
\text { No. }\end{array}$ & $\underset{(\mathrm{g})}{\text { Carbon }}$ & $\begin{array}{l}\mathrm{Al} \\
(\mathrm{g})\end{array}$ & $\underset{(\mathrm{g})}{\mathrm{Al}_{2} \mathrm{O}_{3}}$ & $\underset{(\mathrm{g})}{\mathrm{AIN}}$ & $\underset{(\mathrm{g})}{\text { Sum }}$ & $\begin{array}{l}\% \mathrm{~A} 1 \\
\text { added }\end{array}$ & $\begin{array}{r}\% \mathrm{Al} \\
\text { founded }\end{array}$ \\
\hline \multirow{3}{*}{$\begin{array}{l}\text { Standard } \\
\text { series }\end{array}$} & S-1 & 9.9950 & 0.0050 & & & 10 & 0.05 & \\
\hline & $\mathrm{S}-2$ & 9.9900 & 0.0100 & & & 10 & 0.10 & \\
\hline & S- 3 & 4.9850 & 0.0150 & & & 5 & 0.30 & \\
\hline \multirow{2}{*}{$\begin{array}{l}\text { Unknown } \\
\text { series }\end{array}$} & $\mathrm{U}-4$ & 9.9811 & & 0.0189 & & 10 & 0.10 & $0.11_{2}$ \\
\hline & U-6 & 7.4890 & 0.0025 & 0.0047 & 0.0038 & 7.5 & 0.10 & $0.11_{1}$ \\
\hline
\end{tabular}

\section{Further Tests by Ebert Type Grating Spectrograph}

In the last stage of this research, spectrographic standard samples made by British "Bureau of Analysed Samples Ltd." were available. But, in addition tests were made with the Ebert type grating spectrograph.

The results of the experiments: The results of experiments made with the medium quartz prism spectrograph after correction was made are shown in Table 8.

Ebert type grating spectrograph was 5 meter long, $4.8 \mathrm{~m}$ wide and $1.5 \mathrm{~m}$ high. It was the domestic No. 1 instrument made by Shimazu Seisakusho. However, the grating is the Replica Grating, made by the Baush \& Lomb Co. on which is ruled 600 grooves $/ \mathrm{mm}(1,200 / \mathrm{mm}$ for spare part) with an effective surface of $56 \mathrm{~mm} \times 128 \mathrm{~mm}$.

This grating was coated with aluminium coated by the vacuum spattering method. Therefore, the clarity of the spectrograph in the first order spectra 
is almost equal to that of the medium quartz spectrograph.

The capabilities of this instrument are shown in Table 7 .

Table 7. Dispersion and resolution of the Ebert type grating spectrograph

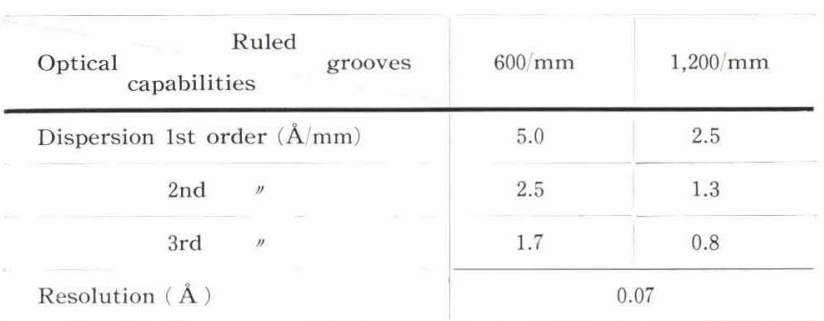

\section{Analytical Line Pair}

According to the results ${ }^{4}$ of studies in this plant, the adjustment of the steel structure is satisfactorily accomplished by setting the normalizing temperature at $925^{\circ} \mathrm{C}$, and by setting the austenite grain size at 7-8. For that purpose, it is necessary that it contains $\mathrm{Al}$ over $0.015 \%$ in form of $\Sigma \mathrm{Al}$, as it has been known.

Then the selection of the analytical line pair becomes necessary so that the index point of the line pair will be around $0.015 \%$. The selected line pairs are those given in Table 8 and the spectrogram is as shown in Photo 3.

\section{Preburn}

The behavior of the above two Fe spectral lines

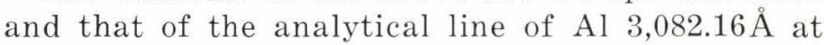
the excitation period were studied by the moving plate method. The results of the study made clear that these three spectral lines acted similarly, and that the intensity ratio of the analytical line pairs each became steady in about $20 \mathrm{~s}$. The profile is shown in Fig. 2.

\section{Plate Calibration}

For the evaluation of spectral intensity, the intensity comparison method (called $\Delta \mathrm{I}$ method) as well as the density comparison methods ( $\Delta \mathrm{S}$ method), were used together. The $\Delta \mathrm{S}-\log \mathrm{C}$ calibration method has the inconvenience of photographing the standard sample and the unknown sample on the same plate during each analysis. With the $\Delta \mathrm{I}-\log \mathrm{C}$ calibration method, the standard sample photographing can be omitted by means of plate calibration. This is an advantage in shortening the analysis time.

For the plate calibration, several methods have been published. ${ }^{10)}$ But the authors adopted, in this

Table 8. Operating conditions

Spectrograph

Dispersion, A/mm
Slit width, mm
Step filter (\% Tr)
Diaphragm
Electrode
Excitation source
Voltage
Amperage
Rate of intermittent arc
Period of intermittent arc
Pre-exposure, sec
Exposure, sec
Analysis line pair
Plate calibration
Developer

Quartz, medium

Grating, Ebert

\begin{tabular}{|c|c|}
\hline 14.9 & 2.4 ( 2 nd order) \\
\hline 0.025 & 0.025 \\
\hline $15 \%, 100 \%$ & $15 \%, 100 \%$ \\
\hline No. 1 & No. 2 \\
\hline $\begin{array}{l}\text { f ( } 1 \mathrm{~mm} \text { sq. roof type }) \\
\text { nt-to-plane } \\
: 1 / 4 \text { inch with } 120^{\circ} \text { tip) }\end{array}$ & $\begin{array}{l}\text { Same as the procedure of } \\
\text { quartz, medium }\end{array}$ \\
\hline $\begin{array}{l}\text { Intermittent Arc } \\
220 \mathrm{~V} \\
\text { ase } 1: 3 \mathrm{~A} \\
\text { ase } 2: 6 \mathrm{~A}\end{array}$ & $\begin{array}{l}\text { A.C. Intermittent Arc } \\
220 \mathrm{~V} \\
\text { Case } 1: 5 \mathrm{~A} \\
\text { Case } 2: 6 \mathrm{~A}\end{array}$ \\
\hline $1: 10$ & $1: 10$ \\
\hline $1 \mathrm{r} \cdot \mathrm{p} . \mathrm{s}$ & 1 r.p.s \\
\hline 10 & 20 \\
\hline $\begin{array}{l}\text { ase } 1: 20 \\
\text { ase } 2: 20\end{array}$ & $\begin{array}{l}\text { Case } 1: 30 \\
\text { Case } 2: 40\end{array}$ \\
\hline \multirow[t]{2}{*}{ e $3116.63 / \mathrm{Al} 3082.16$} & $\begin{array}{l}\text { Al } 3082.16 / \mathrm{Fe} 3093.36 \\
\text { Al } 3082.16 / \mathrm{Fe} 3095.27\end{array}$ \\
\hline & $\begin{array}{l}7 \text { step filter method } \\
\text { Calibration iron line : Fe } 3125.65\end{array}$ \\
\hline uji process & Fuji process \\
\hline $\mathrm{D}-13,\left(20^{\circ} \mathrm{C}, 3 \mathrm{mn}\right)$ & $\mathrm{FD}-\mathrm{R}\left(20^{\circ} \mathrm{C}, 3 \mathrm{mn}\right)$ \\
\hline
\end{tabular}


experiment, 7 steps filter (Hilger Co.) of which relative intensity has been known.

Also the $\gamma$-elimination method, $\left.{ }^{11}\right)$ - (in which two index points are used for eliminating $\gamma$-effect of the plate and working curve is obtained)-will require the same time for analysis $\Delta \mathrm{I}$ method.

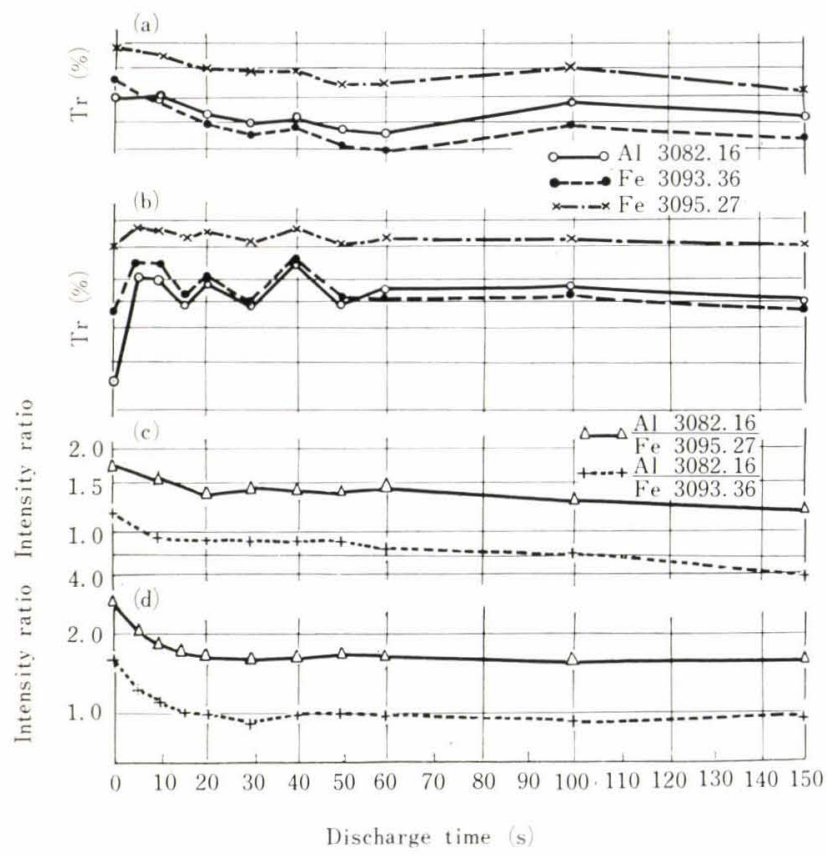

(a) Relationship of per cent transmission of $\mathrm{Fe}$ lines and Al 3082 A vs. discharge time (Dis samplec)

(b) Relationship of per cent transmission of $\mathrm{Fe}$ lines and $\mathrm{Al} 3082 \mathrm{~A}$ vs. discharge time (Pin sample)

(c) Relationship of intensity ratio of analytical line pair vs. discharge time (Disc sample)

(d) Relationship of intensity ratio of analytical line pair vs. discharge time (Pin sample)

Fig. 2. Pre-arc curves

\section{Standard Sample}

In the standard samples made in England (No. SS-11 No. SS-17) which were made for spectrographic analysis of residual elements in mild steel, three kinds of SS-11, SS-12 and SS-14 are given as the standard value of $\Sigma \mathrm{Al}$, while the others are given only the reference values.

So, the authors have determined, with the analytical conditions shown in Table 8, SS-13, SS-16 and SS-17 as unknown samples, on 30 plates for one month, and the results were taken as our standard values.

Those standard values are given in Table 9, and the working curves are shown in Fig. 3.

\section{Precision of This Method}

(a) After shaping and polishing the same sample (forged material) into two kinds of discharge surfaces, pin type and disc type, photographing for determination was repeated nineteen times. The results of this determination showed that with the pin-type sample coefficient of variation was $5.34 \%$, and with the disc-type sample, $3.06 \%$.

(b) For the reproducibility testing over a long period, 57 pictures were chosen from among the plates which had been photographed for about one

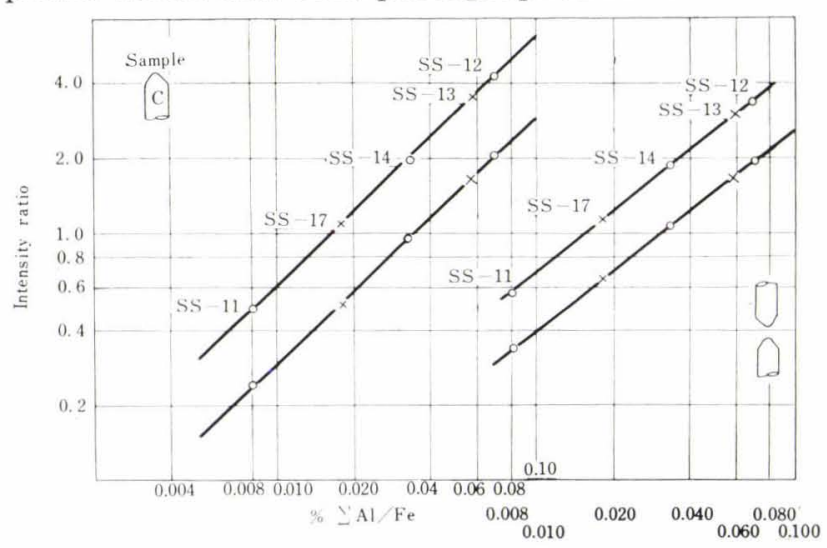

Fig. 3. Working curves using an Ebert type grating spectrograph

Table 9. Standard value of total aluminium (used for analysis with a grating spectrograph)

\begin{tabular}{|c|c|c|c|c|}
\hline $\begin{array}{l}\text { Standard } \\
\text { sample No. }\end{array}$ & $\begin{array}{c}\mathrm{Al} \\
\text { (Total) } \\
\%\end{array}$ & $\begin{array}{c}\mathrm{Al} \\
\text { (Acid sol.) } \\
\%\end{array}$ & Remarks & $\begin{array}{l}\text { Spectral value by } \\
\text { the authors, } \%\end{array}$ \\
\hline \multirow[t]{7}{*}{ S.S. No. 1} & 0.008 & 0.008 & & \\
\hline & 0.068 & 0.064 & & \\
\hline & $(0.060)$ & & Non-standardized & $0.05_{8}$ \\
\hline & 0.032 & 0.029 & & \\
\hline & $(0.020)$ & & Non-standardized & - \\
\hline & $(0.025)$ & & $"$ & 0.024 \\
\hline & $(0.015)$ & & $"$ & 0.018 \\
\hline
\end{tabular}


year and the variation of the index point was studied. The results are shown in Table 10 .

From the results of the experiments for precision in the range of $\Sigma \mathrm{Al} 0.015-0.030 \%$, it was clear that $1 \sigma$ is $\pm 0.001-0.002 \%$. Therefore, in a routine analysis, a precision adequate for practical use presumably would be obtained if the analysis was repeated three times, and the average value taken.

Table 10. Reproducibility of index point

\begin{tabular}{|c|c|c|c|c|}
\hline \multirow{2}{*}{$\begin{array}{l}\text { Analysis } \\
\text { line-pair }\end{array}$} & & \multicolumn{2}{|c|}{ Pin } & \multirow{2}{*}{$\begin{array}{c}\text { Disc } \\
\Delta I\end{array}$} \\
\hline & & $\Delta S$ & $\Delta I$ & \\
\hline \multirow{2}{*}{ Al 3082.16} & $n$ & 57 & 18 & 10 \\
\hline & $X$ & $0.015_{1}$ & 0.0164 & 0.0160 \\
\hline \multirow{2}{*}{$\mathrm{Fe} 3095.27$} & $S$ & $0.0010_{6}$ & 0.00114 & $0.0010_{0}$ \\
\hline & Coeff. of var. & 7.04 & 6.80 & 6.25 \\
\hline \multirow{2}{*}{ Al 3082.16} & $n$ & 57 & 18 & 10 \\
\hline & $X$ & 0.0303 & 0.0312 & 0.0329 \\
\hline \multirow{2}{*}{ Fe 3093.35} & $S$ & $0.0019_{8}$ & $0.0011_{7}$ & $0.0019_{2}$ \\
\hline & Coeff. of var. & 6.52 & 3.75 & 5.84 \\
\hline
\end{tabular}

6. Accuracy of This Method

(a) The results of spectrochemical determination compared with the results obtained after repeating the chemical analysis seven times with the samples (explained in item (a) of the proceeding chapter) when analysed by Bartlet test, as shown in Table 11, show no significant difference among the three variances of analytical values in the pin-sample method, disc-sample method and chemical-analysis method.

(b) With regard to ladle samples, bloom samples or billets etc., the results of analysis on their pin sample or disc sample by this method were compared with their chemical analyses. No significant difference was observed as shown in Table 12 .

\section{Time Required for Analysis}

The time required for this method was measured from the starting of the arranging of the sample to the reporting of the results.

It was found that in case of the only one sample, the length of time was in the order of $\Delta \mathrm{S}$ method, $\Delta \mathrm{I}$ method and $\gamma$-elimination method, 45 min., $25 \mathrm{~min}$. and $24 \mathrm{~min}$, respectively.

In the case of analyzing several consecutive charges continuously, it was found that in two hours, 20 samples could be analyzed by $\Delta \mathrm{I}$ method or $\gamma$-elimination method.

Table 11. Bartlett test of variance ratio

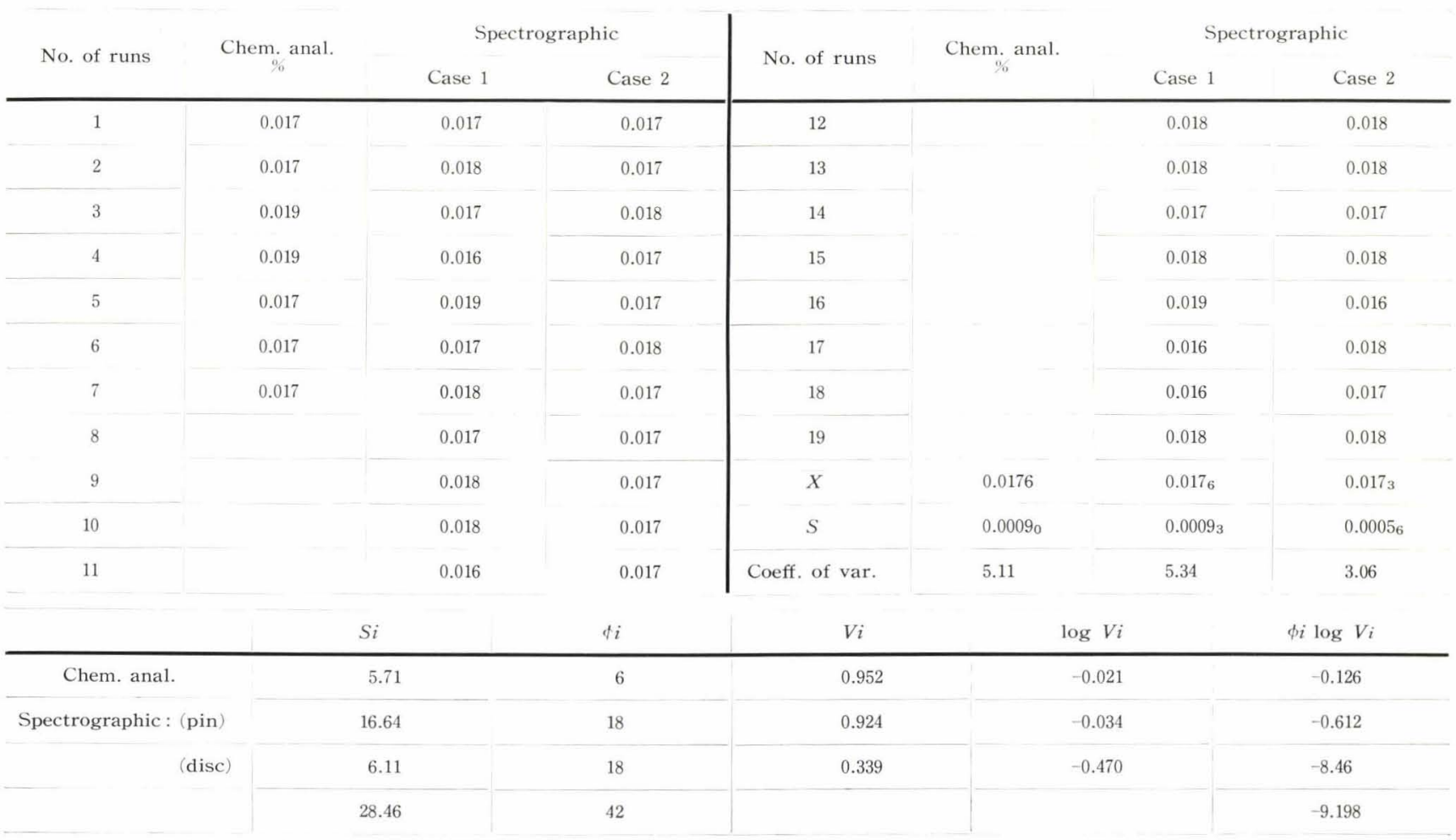

(Note) $x^{2}=2.3026\left(\phi \log V-\Sigma \phi_{i} \log V i\right)$ $=3.45\left(5.99-\chi_{2}^{2}(0.05)\right)$ 
On the other hand, in the chemical analysis methods (such as mercury-cathode electrolysis aluminon spectrophotometric method), only four items could be analyzed in two hours. Therefore, this method, compared with chemical analysis method, has an analysis efficiency of 3-5 times. Subsequently the cost of analysis can be reduced about one third.

The equation of regression is already established in the relation of the correlation of $\Sigma \mathrm{Al}$ contents between ladle sample and bloom itself. ${ }^{6)}$ The $\Sigma$ Al content of the bloom can be estimated from the value of the spectrochemical analysis of the ladle sample. The effect of grain adjustment at this stage becomes clear in 3-4 hours after ingot making.

Thus, this method presents the guide for proper handling of the ingot afterward and for securing a good quality of product.

\section{Conclusion}

The establishing of prompt and accurate analysis of minute aluminum in steel, was studied with a medium spectrograph and an Ebert type grating spectrograph with the A.C. intermittent arc method, and a satisfactory method of routine analysis was well established.

The results of the present experiment are sum- marized as follows:

(1) According to this discharge method, no evaporation phenomenon of fractional distillation could be observed.

(2) The range of determination was $\Sigma \mathrm{Al} 0.005-$ $0.100 \%$.

(3) When the second order spectra (dispersion: $2.5 \AA / \mathrm{mm}$ ) of the grating spectrograph were used, the precision was as follows. With pin sample, the precision was $5.34 \%$. With disc sample it was $3.06 \%$, and there was no significant difference between the values of analyses of ladle sample, bloom sample and billet sample by this method, and the chemical analysis.

(4) By analyzing the ladle sample by this method, the grain adjusting effect was found in 3-4 hours after the ingot making.

\section{Acknowledgement}

The authors express their appreciation to K. Narita, T. Noda, K. Kunii and M. Ishibashi of Kobe Research Department for their helpful suggestions.

\section{REFERENCES}

1) Zenichiro Takao, Takaaki Shimose, and Kiichi Narita : Kobe Seiko, 5 (1955) 103

2) Zenichiro Takao, Takaaki Shimose, Kiichi Narita and Kazuo Kunii : ibid, 5 (1955) 103

Table 12. Data on accuracy

\begin{tabular}{|c|c|c|c|c|c|c|c|c|c|c|c|c|c|c|}
\hline \multicolumn{10}{|c|}{ Pin samples } & \multicolumn{5}{|c|}{ Disc samples } \\
\hline \multicolumn{5}{|c|}{ Ladle- $\Delta S$ method } & \multicolumn{5}{|c|}{ Bloom- $\Delta S$ method } & \multicolumn{5}{|c|}{ Billet- $\Delta I$ method } \\
\hline $\begin{array}{l}\text { Heat } \\
\text { No. }\end{array}$ & Type & Chem. & Spect. & Diff. & $\begin{array}{l}\text { Heat } \\
\text { No. }\end{array}$ & Type & Chem. & Spect. & Diff. & $\begin{array}{l}\text { Heat } \\
\text { No. }\end{array}$ & Type & Chem. & Spect. & Diff. \\
\hline 1892 & F 5 & 0.014 & 0.012 & -2 & 1896 & STF $42 \mathrm{D}$ & 0.011 & 0.011 & 0 & 14 & $\mathrm{Ni}-\mathrm{Cr} 1$ & 0.004 & 0.005 & 1 \\
\hline 695 & $"$ & 0.021 & 0.024 & 3 & 2473 & SCM 21 & 0.029 & 0.026 & -3 & 16 & $10 \mathrm{C}$ & 0.065 & 0.065 & 0 \\
\hline 9856 & $\nu$ & 0.019 & 0.020 & 1 & 3985 & F 5 & 0.019 & 0.020 & 1 & 23 & $\mathrm{Cr}-\mathrm{Mo}$ & 0.010 & 0.009 & -1 \\
\hline 9899 & , & 0.015 & 0.019 & 4 & 3987 & " & 0.012 & 0.013 & 1 & 29 & " & 0.012 & 0.012 & 0 \\
\hline 1873 & SH 85 B & 0.028 & 0.030 & 2 & 3994 & " & 0.017 & 0.019 & 2 & 30 & $\mathrm{Ni}-\mathrm{Cr}$ & 0.007 & 0.010 & 3 \\
\hline 1783 & F 5 & 0.013 & 0.017 & 4 & 3995 & $"$ & 0.017 & 0.018 & 1 & 31 & SAE 8630 & 0.011 & 0.011 & 0 \\
\hline 9915 & SH $85 \mathrm{~B}$ & 0.031 & 0.030 & -1 & 4042 & " & 0.012 & 0.014 & 2 & 32 & Fs 1117 & 0.004 & 0.005 & 1 \\
\hline 1902 & F 5 & 0.017 & 0.022 & 5 & 4623 & " & 0.019 & 0.019 & 0 & 438 & SCM 3 & 0.018 & 0.018 & 0 \\
\hline 1883 & " & 0.019 & 0.016 & -3 & 5004 & " & 0.017 & 0.015 & -2 & 498 & $"$ & 0.020 & 0.017 & -3 \\
\hline 1867 & " & 0.018 & 0.017 & -1 & 5033 & " & 0.016 & 0.018 & 2 & 642 & $\mathrm{SCM} 2$ & 0.015 & 0.016 & 1 \\
\hline 267 & " & 0.015 & 0.015 & 0 & 5114 & SFA 55 & 0.021 & 0.021 & 0 & 854 & $\mathrm{SNC} 22$ & 0.026 & 0.029 & 3 \\
\hline 672 & $"$ & 0.010 & 0.009 & -1 & 5115 & " & 0.024 & 0.022 & -2 & 863 & $\mathrm{SNC} 2$ & 0.013 & 0.014 & 1 \\
\hline 706 & SCM 21 & 0.018 & 0.020 & 2 & 5116 & " & 0.021 & 0.023 & 2 & 6607 & " & 0.011 & 0.008 & -3 \\
\hline 1328 & " & 0.023 & 0.022 & -1 & 5705 & F 5 & 0.019 & 0.016 & -3 & 8600 & SCM 3 & 0.017 & 0.017 & 0 \\
\hline 1448 & F 5 & 0.016 & 0.014 & -2 & 5706 & " & 0.020 & 0.021 & 1 & 8606 & $"$ & 0.016 & 0.019 & 3 \\
\hline 3664 & y & 0.017 & 0.016 & -1 & 5707 & " & 0.021 & 0.020 & -1 & 8842 & $\mathrm{SNC} 2$ & 0.013 & 0.015 & 2 \\
\hline 1555 & " & 0.020 & 0.017 & -3 & 5955 & " & 0.019 & 0.020 & 1 & 9031 & " & 0.013 & 0.012 & -1 \\
\hline \multirow[t]{4}{*}{1571} & ” & 0.017 & 0.019 & 2 & 6055 & " & 0.012 & 0.013 & 1 & 9264 & " & 0.016 & 0.015 & -1 \\
\hline & & & & & 6056 & $"$ & 0.019 & 0.021 & 2 & $\mathrm{D}-4$ & SCM 21 & 0.035 & 0.032 & -3 \\
\hline & & & & & 6057 & ” & 0.018 & 0.017 & -1 & D 6 & " & 0.027 & 0.025 & -2 \\
\hline & & & & & & & & & & D-7 & " & 0.029 & 0.029 & 0 \\
\hline \multicolumn{5}{|c|}{$\begin{array}{l}n=18 \quad d=0.0004 \quad \sigma_{\mathrm{e}}=0.0025 \\
t_{0}=0.73<t(17,0.05)=2.110\end{array}$} & \multicolumn{5}{|c|}{$\begin{array}{l}n=20 \quad \bar{d}=0.0002 \quad \sigma_{\mathbf{e}}=0.0017 \\
t_{0}=0.54<t(19,0.05)=2.093\end{array}$} & \multicolumn{5}{|c|}{$\begin{array}{l}n=21 \quad \bar{d}=0.0002_{4} \quad \sigma_{\mathrm{e}}=0.0018 \\
t_{0}=0.599_{5}<t(20,0.05)=2.086\end{array}$} \\
\hline
\end{tabular}


Zenichiro Takao, Tadao Noda, Kazuo Kunii and Hisashi Takada: Suiyokaishi (J. Almuni Assoc., Metallurgical Dept., Kyoto Univ.), 13 (1956) 51, 107

3) Zenichiro Takao, Tadao Noda, Kiichi Narita, Kazuo Kunii and Hisashi Takada: Kobe Seiko, 6 (1955) 3

4) Taira Nakano, Kazuo Kunii, Minoru Makioka and Masaharu Kitazima: Kobe Seikosho Kenkyuhokoku (Research Report, Kobe Steel Works, Ltd.), No. 1071 (1958)

5) R. Castro: Spectrochemica Acta., 3 (1946) 18

6) O. Schliessman: Arch. f. Eisenhüttenw., 13 (1940) 295

7) C. G. Carlsson: Jern Kontorets Annaler, 126 (1942) 161

8) R. H. Colin, D. A. Gardner: Anal Chem., 21 (1947) 701

9) G. E. Ressler: Journal of Metals, Dec. (1954) 1622

10) ASTM (Committee E-2): Methods for Emission Spectrochemical Analysis, (1957)

11) Hiroshi Iizima: Journal of the Spectroscopical Society of Japan, 7 (1954) 23 